\title{
EL PROCESO CONSTITUYENTE ESPAÑOL VISTO POR UNO DE SUS PROTAGONISTAS: ENTREVISTA A ÓSCAR ALZAGA VILLAAMIL
}

\section{THE SPANISH CONSTITUENT DEBATES AS SEEN BY ONE OF ITS PROTAGONISTS: AN INTERVIEW TO OSCAR ALZAGA VILLAAMIL}

\author{
Óscar Alzaga Villaamil \\ Universidad Nacional de Educación a Distancia
}

\begin{abstract}
Historia Constitucional: Profesor Alzaga. En un Parlamento como el actual, muy fragmentado y en el que las divisiones ideológicas generan un estado de crispación más acusado que en anteriores asambleas, no estaría de más conocer, a través de su experiencia, cómo considera que fue la relación entre las distintas fuerzas politicas que formaban la Asamblea Constituyente en un momento, además, en el que se trataba de sumar y de avanzar para sacar adelante un texto que dejase atrás la dictadura.
\end{abstract}

HC.- Usted forma parte de un grupo de profesores de Derecho Politico que actuaron en la Asamblea Constituyente y que, además, ideológicamente se hallaban muy distantes, como Manuel Fraga o Jordi Solé Tura. ¿Existía algún tipo de relación especial entre Vds.? ¿Se entendian mejor por esa común formación jurídico-politica? $Y$, sobre todo, ¿cuál considera que fueron sus aportaciones que pudieron ofrecer al diseño de la Constitución a partir de sus conocimientos teóricos?

En los trabajos de Comisión y de Pleno del Congreso de los Diputados -y sobre todo en las reuniones de negociación a puerta cerrada- naturalmente resultó muy útil la relación de confianza reciproca que cada diputado pudiera tener con otros parlamentarios de otros grupos. Creo sinceramente que con quienes habíamos forjado una sincera amistad desde hacía bastantes años, pudimos hablar con dosis de claridad y sinceridad que resultaron muy operativas.

La pregunta que se me hace se refiere especificamente a profesores de Derecho político y se menciona especialmente a Manuel Fraga y a Jordi Solé Tura. Pero, antes de referirme a ambos, debo especificar la relación de amistad mía con profesores de la ponencia y de la Comisión. Creo que he de destacar la que mantenía desde muy joven con Gregorio Peces Barba, por entonces profesor agregado de Filosofía del Derecho, que poco después accedería a la condición de Catedrático, a la de Presidente del Congreso de los Diputados y seguidamente a la de Rector de la Universidad Carlos III. Con Gregorio yo había compartido el esfuerzo de poner en marcha "Cuadernos para el Diálogo", de que fuimos cofundadores, la organización ilegal denominada "Unión de Jóvenes Demócratas Cristianos", muy pronto reconocida por la Internacional, y compartimos responsabilidades politicas en la oposición democrática, en la defensa de los derechos y de las libertades de muchas personas, recurriendo expedientes sancionadores, poniéndonos la toga ante el Tribunal de Orden 
Público y desplegando numerosas actividades que no creo necesario citar aquí, pero que no cesaron cuando él a la altura de 1970 se incorporó al PSOE. El profesor Peces-Barba fue el autor del texto sobre el que se trabajó para la redacción en ponencia del Título I CE y, como era el único miembro del PSOE en la ponencia, formó una discreta comisión de apoyo, integrada por profesores de Derecho Político con los que yo tenía buena relación, si bien nunca le puenteé y procuré mantener todos los diálogos importantes directamente con él. Nuestra amistad y nuestra confianza recíproca creo que fue utilísima para superar numerosos atascos y encontrar un importante número de soluciones transaccionales sobre puntos delicados a lo largo del texto constitucional; y también a la hora de desarrollar nuestra carta magna a través de diversas leyes orgánicas, tanto cuando surgieron problemas politicos serios que hicieron temblar acuerdos ya alcanzados -como sucedió con la Ley Orgánica del Tribunal Constitucional, tras superar los trabajos en la Comisión, al iniciarse los debates en el Pleno del Congreso-, como cuando en ponencia él -que naturalmente actuaba como portavoz del PSOE- y yo -como portavoz de UCD- consensuábamos mano a mano la práctica totalidad de una ley, de lo que fue buen ejemplo la Ley Orgánica del Defensor del Pueblo.

En lo que concierne al profesor Fraga Iribarne, mi relación era mínima, porque él llevaba muchos años con escasa dedicación a su condición profesoral por ocupar sucesivamente cargos politicos. Además, su pleno alineamiento con el Régimen anterior suponía una distancia objetiva importante con quienes militábamos en un partido ilegal. Mi primer contacto indirecto con Manuel Fraga se había producido con motivo de que él estaba entre los promotores del diario "El País" y siendo Ministro de Información Pio Cabanillas no se atendía la solicitud de inscripción en el Registro de medios de comunicación; entonces había preguntado a la Asesoría Jurídica del Ministerio que abogado le recomendaban para que llevase el Recurso contra la denegación de inscripción por silencio administrativo y le habian hablado de mi diciéndole que hacía unos buenos escritos em materia de sanciones por presuntas infracciones del artículo $2^{\circ}$ de la Ley de Prensa y que sobre todo era muy pragmático y prefería siempre llegar a una transacción a un lucimiento en la vista oral a celebrar ante la Sala Tercera del Tribunal Supremo. Seguidamente Fraga contactó con su amigo el profesor Sanchez Agesta, que había sido el Director de mi tesis doctoral, para que le facilitase mi teléfono, pero no me llamó personalmente él, sino el entonces Presidente de PRISA, José Ortega. Lo que fue toda una prueba de que Fraga pensaba más factible que yo aceptara el encargo si se me pedia por conducto diferente a su persona. Y efectivamente acepté redactar un prolijo escrito denunciando la mora, que, por cierto, se me pagó con extrema generosidad.

Dicho en otras palabras, yo no tenía relación previa con él, a diferencia de Gabriel Cisneros, Miguel Herrero y José Pedro Pérez Llorca, que le conocian desde hacía bastantes años. Por otra parte, Manuel Fraga fue dejado fuera de las discretas sesiones nocturnas que configuraron una especie de segunda ponencia informal. Y cuando llegaron los debates en la Comisión y en el Pleno del Congreso, asumí en varias ocasiones defender los nuevos textos consensuados, respecto de los que el profesor Fraga sostendría sus enmiendas. La inteligencia político-práctica de Fraga no me corresponde cuestionarla, pero su formación 
como profesor de Derecho Político no era moderna y no estaba familiarizado con el constitucionalismo europeo de la época que inevitablemente era el principal referente de Derecho comparado, a la hora de optar por soluciones institucionales y de afinar en la redacción sobre la composición y las funciones de los diversos órganos.

Llegué a las tareas constituyentes con una buena relación personal con Jordi Solé Tura, al que había conocido en 1972 cuando ambos concurrimos en unas oposiciones nacionales al cuerpo de profesores adjuntos de Universidad. Se produjo la paradoja de que militando yo en la Izquierda Demócrata Cristiana y él en el PSUC, D. Torcuato Fernández Miranda, que presidía el Tribunal se empeñó en que no se me concediese el número uno, lo que finalmente no logró pues el resto de los miembros del Tribunal le dejaron solo en ese propósito. Jordi fue muy solidario conmigo al tener noticia de la actitud de Fernandez Miranda. Y alli empezó nuestra buena química, que se prolongó cuando en 1975 ambos coincidimos con otros cuatro amigos como candidatos a la plaza de profesor agregado de Derecho Politico de la recién creada Facultad de San Sebastián, ocasión en que el Consejo de Ministros había instruido al Ministro de Educación para que enviase mensaje a los miembros del Tribunal sobre la no pertinencia de que me dieran la plaza; en lo que tampoco tuvieron éxito.

Ahora bien, la buena relación con Jordi, que nos permitió dialogar mano a mano con confianza sobre las dificultades a solventar en Comisión, produjo escasos efectos fructíferos, pues él oscilaba en las reuniones de trabajo apoyando bien las propuestas del PSOE, bien las sugerencias de Miquel Roca y desde UCD se había optado por tener relación directa bien con los parlamentarios socialistas que asistían a las reuniones, bien con el propio Miquel. Jordi era un tipo estupendo, que estaba pasando del eurocomunismo a la social democracia y que mantuvo una posición muy constructiva y para nada problemática en aquellas innumerables sesiones para mejorar el texto aprobado en la ponencia. Aunque no era exactamente un constitucionalista, en la acepción en que hoy entendemos el término, su formación teórica -que incluía amplios conocimientos de la historia politica y constitucional española- le permitía hacer aportaciones útiles en casi todas las sesiones en que participaba, si bien el hecho de representar al PSUCPCE le dejaba en los bordes del núcleo del consenso.

No me preguntan ustedes por dos catedráticos que fueron diputados constituyentes, Enrique Tierno y Raúl Morodo. Ellos y su partido, el PSP, como todos recordamos fueron dejados al margen de la ponencia, al igual que el PNV, en una decisión de los restantes partidos que en mi modesta opinión debe hoy ser calificada de errónea. Con ambos tenía desde hacía bastantes años una óptima relación personal, que continuaría después. A los dos se les debe el buen texto del Preámbulo de nuestra Constitución y la redacción del artículo sexto, que como sabemos estableció que la organización y funcionamiento de los partidos políticos debería ser democrático, lo que fue aceptado por los restantes partidos en liza, aunque con notorio escaso entusiasmo.

Procuré, durante los trabajos noctámbulos para consensuar textos, reuniones durante los meses de trabajo de la Comisión, en que también a instancias del PSOE se dejó al margen a Tierno y a Morodo, invitar a D. Enrique a varios cafés mano a mano, para informarle de lo que estábamos hablando y 
pedirle su opinión. Él me agradeció mucho esa deferencia, que en mi opinión era lo mínimo que se merecía. Probablemente en recuerdo de esto, D. Enrique me elogia en demasía en un renglón de su librito de memorias "Cabos sueltos", en que se refiere a mi con estas palabras: "Le encontraba con frecuencia y día a día confirmaba la idea de ser uno de los constitucionalistas más capaces y cultos y de las inteligencias más finas que se colocaron en el sector conservador" (p. 335). Elogio inmerecido hacia mí, que lo que si denota era el sólido aprecio recíproco que siempre nos profesamos. Y que se demostró cuando siendo Alcalde de Madrid, poco antes de fallecer, para el acto entrega del ABC de Oro, en junio de 1985, tras vetar la asistencia de Felipe González y de todos los miembros del Gobierno socialista, así como la de Manuel Fraga -y a los otros seis miembros de la ponencia constitucional- y demás dirigentes de Alianza Popular, facilitó la lista de amigos a invitar, dejando claro que su amigo Óscar se sentaría a su lado, de forma que a mí me correspondería hacer su semblanza. Tuve la impresión de que la excelente cabeza de D. Enrique había llegado a la conclusión de que yo era el único parlamentario ajeno a su partido al que había interesado, durante el proceso constituyente, conocer su docta opinión sobre los complejos temas a los que se buscaba solución en discretas reuniones a las que Tierno nunca fue invitado.

HC.- Suele decirse que la filtración del anteproyecto constitucional supuso un incremento de las presiones sobre la Asamblea Constituyente. ¿Sintió Vd. esta circunstancia? ¿Diría que de algún modo afectó al resultado final del texto?

Efectivamente en la etapa final de los trabajos de la ponencia, en noviembrediciembre de 1977, hubo filtraciones significativas a los medios de comunicación sobre discrepancias de sus miembros, acerca de algún desplante en su seno e incluso se facilitó el texto del borrador de anteproyecto a la revista "Cuadernos para el Diálogo", que publicó los primeros treinta y nueve artículos en su número 239. Nunca se aclaró la autoría de esta filtración pues ninguno de los ponentes admitió su relación con la misma. Es verdad que Gregorio Peces-Barba pertenecía -como también yo- al grupo de fundadores de Cuadernos, pero también dos ponentes habían escrito en sus páginas y tenían buen acceso a la redacción. Mi amigo Gregorio dimitió como consejero de Cuadernos con este motivo. Y el 25 de octubre de 1977, El País publicó el texto íntegro de este borrador, cedido por Cuadernos para el Dialogo.

No estoy seguro de que sea certera la premisa que quizá late bajo esta pregunta acerca de una presión negativa sobre los constituyentes. Por lo que llegué a saber, cuando el texto redactado por la Ponencia se filtra los trabajos de la misma estaban bloqueados y el clima de consenso se había evaporado en buena medida. Por ejemplo, el eje formado entre los tres ponentes de UCD (Gabi Cisneros, Miguel Herrero y José Pedro Pérez LLorca) y Miguel Roca entorno al Título VIII había descartado por entero la alternativa federal que el profesor Peces-Barba como ponente del PSOE (que contaba, como ya hemos apuntado, en la rebotica con la colaboración de varios constitucionalistas) intentó sacar adelante sin éxito y mantuvo como enmienda. Pero el PSOE que aceptaba casi todo el articulado del Título I sobre los derechos y deberes fundamentales, mantenía discrepancias significativas respecto de los restantes Títulos, incluyendo la composición del Congreso de los Diputados y del Senado, la estructura del Consejo General del Poder Judicial... por lo que formalmente 
mantuvo viva una enmienda sobre la forma de gobierno y otras muchas de gran alcance. Hasta el punto de que el profesor Peces-Barba abandonó la ponencia y esta cerró sus trabajos sin él. Y la preocupación por aquel estado de cosas estaba muy extendida y llegaba al Gobierno. ¿La filtración buscaba evitar la imagen ante la opinión pública de un amplio consenso? ¿Se intentaba con aquella convulsión superar un bloqueo para abrir una amplia renegociación?

Cuando a fines de diciembre de 1977 a este modesto profesor se le telefonea desde las alturas del Ministerio de Justicia -donde radicaba aún el gozne entre el quehacer constituyente y el Gobierno- para decirme que se me necesitaba y que habian pensado en nombrar Fiscal Jefe del Reino al diputado Juan Manuel Fanjul, para que corriese la lista de UCD por Madrid y tomara yo posesión del escaño, si yo asumía el compromiso de volcarme en la tarea constituyente, la situación era de bloqueo muy complejo. En aquellos días unos me hablaron del Título VIII y otros de diversos preceptos que los ponentes habían sacado adelante con escaso consenso y con toda suerte de dudas. Al incorporarme a principios de enero de 1978 me tocó vivir aquel clima grisáceo. Después de aterrizar de lleno en los trabajos constituyentes, a lo largo de mayo y junio -en que desplegamos un gran esfuerzo en reuniones permanentes $y$ frecuentemente noctambulaslogramos recomponer un consenso mínimo para que saliese de la Comisión de Asuntos Constitucionales y Libertades Públicas del Congreso un texto que la mayoría de los grupos consideraban mejor, aunque ciertamente con abundantes reservas por parte de A.P.

Con otras palabras, podriamos decir que la Ponencia no habia terminado su labor en forma brillante. De su atasco salimos mediante otra forma de trabajar y dialogar durante la fase, realmente capital, de tramitación en la Comisión del Congreso. Para empezar el equipo de la "segunda y nocturna ponencia", como la describió algún medio de comunicación, variaba parcialmente de composición. Suarez sustituyó como coordinador desde el Gobierno a Landelino Lavilla -que solo continuó tutelando el Título VI (del Poder Judicial)- por su amigo Fernando Abril, ingeniero agrónomo (sic). El PSOE reforzó a Gregorio Peces-Barba con Alfonso Guerra, perito industrial (sic) y con el miembro del PSC Martín Toval, inspector de trabajo malagueño (sic). UCD nos incorporó al catedrático de Derecho Administrativo José Luis Meilan Gil y a mí. Se prescindió de Miguel Herrero de Miñón desde fin de mayo. Se invitó a estos trabajos al PNV -del que se habia prescindido por error-, que estuvo representado por su Secretario General, Xavier Arzallus. Y continuaron en los trabajos, Gabriel Cisneros, José Pedro Pérez LLorca, Miguel Roca y Solé Tura. Quizá el cambio más importante consistió en prescindir por entero de Manuel Fraga y de cualquier otro diputado de Alianza Popular, para poder "centrar" nuestra Ley de Leyes.

Es imposible resumir en esta entrevista los amplísimos cambios efectuados, bastantes de ellos de verdadero calado. Entre los más relevantes cabe recordar que sobre el artículo 85 del informe de la Ponencia -en su apartado cuarto reconocía a Comunidades Autónomas la iniciativa de convocar referéndums para derogación de leyes- mostramos nuestra mayor preocupación quienes nos habíamos incorporado al equipo negociador e intuíamos la complejidad de un Estado autonómico en que algunas comunidades podian estar gobernadas por dirigentes nacionalistas. Tras complejas negociaciones se consiguió modificar ampliamente el precepto y 
suprimir este apartado, lo que se incorporó mediante una enmienda in voce, consensuada por buen número de grupos parlamentarios, pero al que negó su apoyo Alianza Popular. La enmienda fue defendida por Jordi Solé-Tura y Manuel Fraga hizo pública su discrepancia. La historia se ha encargado de probar que el profesor Solé-Tura era más conservador en el mejor sentido del término que el ex ministro Fraga, que habia jugado un papel relevante en el referéndum huérfano de garantías con el que se refrendó en 1967 la LOE. Si lo pensamos bien, en ello había un comportamiento menos paradójico de lo que podia parecer en cuantos intervenimos en aquel delicado y pertinente cambio.

Por todo ello quizás alguien, menos académico que quien contesta, podría decir sobre la filtración del borrador de la Ponencia que, según el viejo adagio, Dios escribe derecho con renglones torcidos.

HC.- La distancia entre el anteproyecto constitucional, por un lado, y el proyecto aprobado por la Comisión de Constitución fue muy notable. ¿Cuáles diría que fueron los aspectos en los que la diferencia resultó más acusada?

Efectivamente, las modificaciones introducidas por la Comisión de Asuntos Constitucionales y Libertades Públicas del Congreso fueron muy significativas. Sin ambición de exhaustividad, pues la pormenorización equivaldría a escribir aquí toda una monografia, subrayaremos las que nos parecen más relevantes.

En el Título II se optó en Comisión por la asunción de un modelo de monarquía parlamentaria europea homologable con las restantes, bien del Benelux, bien del norte de nuestro continente. Toda fórmula ambigua respecto de una monarquía constitucional fue sustituida por los parámetros propios de la monarquía parlamentaria europea de la época.

Del Título III, relativo a las Cortes Generales se pueden anotar muchas modificaciones puntuales, pero mayor calado tuvo el debate sobre la composición del Senado, respecto de cuya composición los partidos de izquierda mantuvieron enmiendas. Ante la defensa numantina desde las alturas de UCD de la composición prevista en la Ley para la Reforma Política, solo se cedió en la inclusión del apartado 5 del artículo 69, relativo, como sabemos, a que las Comunidades Autónomas designan un senador y otro más por cada millón de habitantes.

El Título IV venía de ponencia instituyendo con énfasis la independencia del poder judicial. Premisa esencial esta de todo Estado de Derecho que se perfeccionó en lo posible, tras un debate infinitamente extenso sobre la composición del Consejo General del Poder Judicial, que no dejó a nadie buen sabor de boca sobre la fórmula finalmente consensuada.

El Título VIII fue objeto de innumerables modificaciones, no siempre aplaudibles, como sucedió, para satisfacer al nacionalismo vasco y catalán, con la inclusión del artículo 150.2, pactado en el despacho de Fernando Abril sin habérseme convocado pues había destacado por mi oposición ante una fórmula sin precedentes en el constitucionalismo federal europeo. Tan acusada era mi discrepancia que cuando publiqué mi libro "Comentario Sistemático a la Constitución Española de 1978", que salió a las librerias en la semana siguiente a la celebración del referéndum, opté por suprimir los tres folios de crítica sin paliativos que había redactado respecto del mismo y me limité a reproducir 
entrecomillados unos párrafos de la defensa de este apartado efectuada en el hemiciclo del Congreso por el portavoz de UCD con argumentos que yo no podia asumir. Desde mi pública preocupación por haberse optado por un Título VIII inacabado, abierto, que constituía el campo ideal para los nacionalismos deseosos de practicar la reivindicación permanente, que diría Trotsky, incluí en la primera página de la introducción al estudio de este Título, en mi mismo libro, la siguiente afirmación: "Estamos en presencia no solo del Título más polémico de la Constitución, quizá porque es reflejo del debatido art. 2, cuya glosa bien podría habernos servido de preámbulo a estas palaras, sino sobre todo porque la confrontación de las posiciones políticas divergentes en cuanto a la concepción de la Organización Territorial del Estado, en el seno de la Ponencia nombrada inicialmente por el Congreso arrojó un texto de partida que, aunque muy modificado, ha subsistido en lo fundamental y que politicamente puede obtener un juicio a su favor más o menos favorable, según la óptica subjetiva desde la que sea contemplado, pero que es dificil de calificar desde una perspectiva técnico-jurídica con benevolencia. La falta de opciones claras en torno a algunos puntos básicos del Título y la falta de sistemática, que sobre algunos aspectos es casi absoluta, nos permiten atrevernos a profetizar que los especialistas harán una dura critica del nivel de técnica legislativa que arroja al articulado de este Título y en especial del de su Capítulo Tercero, que, desde luego, es el meollo de aquel". Ni que decir tiene que, mi opinión no estaba aislada; recuerdo que, a mitad del curso 1978/79, me llegó la información de que D. Francisco Murillo, que explicaba con su ameno verbo la nueva Constitución a los alumnos de la Facultad de Derecho de la Universidad Autónoma de Madrid, una mañana comenzó su lección en el aula con estas palabras: "Hoy ya nos toca el Título VIII; es como si paseando por el zoológico hubiésemos llegado a la jaula de la jirafa y un joven hijo nuestro dice no es posible. Nosotros le hemos de decir mirando su pescuezo: si que es posible, es el Titulo VIII". D. Francisco, que era sin duda por entonces nuestro constitucionalista que sabía más de las dinámicas que estudiaba la politología contemporánea, leía ya como avanzarían los nacionalismos infra estatales por las pistas expeditas que ofrecía aquel Título enteramente abierto.

HC.- En la Constitución española son perceptibles huellas de otros textos constitucionales foráneos, como las Constituciones de Portugal, Francia, Italia y Alemania. ¿Defendió Vd. alguno de estos modelos extranjeros para implantarlo en el proceso constituyente? ¿Qué autores del Derecho Constitucional europeo actuaban para Vd. y sus colegas de Derecho Politico como referentes en la fase constituyente?

Desde mi formación, o desde mi deformación -pues no hay formación que no conlleve cierta deformación- presté siempre atención a los modelos que ofrecian el Derecho constitucional europeo de la segunda postguerra mundial y al más reciente, representado por las Constituciones portuguesa y sueca.

Pero naturalmente la mayoría de los constituyentes no eran profesores de nuestra disciplina. Desde la ladera más conservadora subsistía un referente poco confesado, pero que se tenía muy presente y era el constitucionalismo de la restauración, que, como es bien sabido, había perdurado durante varias décadas. El texto de 1876 en muchos sentidos no era adjetivable de constitución normativa, según la terminología de Loewenstein, pero había permitido que, tras una fachada constitucional más o menos homologable con las usuales en su 
época, subsistiese una estructura caciquil, un sufragio adulterado y unas dinámicas presididas por unas corruptelas cada vez más visibles por la opinión pública y más rechazadas por la intelectualidad de la época. Aquella monarquía no era parlamentaria, sino meramente constitucional y la dura realidad de aquel sistema acabó enterrando la propia forma de gobierno monárquica. De aquel periodo constitucional poco había que admirar, pero ese era el modelo que tenían más presente personas que, como Torcuato Fernández Miranda, habían jugado un papel importante en el diseño de los primeros pasos de nuestra transición y de la Ley para la Reforma Politica. La actitud de Fraga en la ponencia, las enmiendas de López Rodó en la Comisión y tantos otros pasos de los que hay prueba documental en el Boletín de las Cortes o en el Diario de Sesiones del Congreso de los Diputados ofrecen indicios o pruebas de todo ello. Frente a ese esfuerzo retardatario, la invocación del Derecho Constitucional europeo vigente era poner como modelo el único invocable para construir un Estado social y democrático de Derecho parangonable con el de los países miembros de la Comunidad Económica Europea de la que aspirábamos a formar parte.

El PSOE trabajaba con ciertas notas de Derecho Constitucional comparado preparadas por la Comisión en la sombra de profesores de Derecho Político, a que ya hemos hecho referencia. Cuando yo me incorporé en enero de 1978 a la Comisión Constitucional y al equipo noctámbulo de negociación, percibí que los ponentes de UCD no tenían unas notas de Derecho Constitucional europeo manejables para los debates pendientes sobre el alto número de cuestiones que seguían vivas en el debate. Preparé por mi cuenta esas notas, que me servirian en agosto, al dictar mi citado libro "Comentario sistemático a la Constitución española de 1978", en que al iniciar el comentario de cada artículo de nuestra Constitución incluí, tras unos apartados sobre antecedentes del proceso de elaboración parlamentaria del precepto y sobre precedentes históricos, otro denominado Derecho comparado, que resumía los modelos foráneos que yo había tomado en consideración. Dejé así, con la mayor transparencia, constancia de lo que había tenido en cuenta en los debates; mientras que naturalmente puede deducirse también que lo alli no reflejado no lo había tomado en consideración. Como no pocos diputados de UCD a los que correspondió intervenir en los debates -pues procuramos que buena parte de los miembros del grupo parlamentario subieran a la tribuna- me pedian alguna nota escrita sobre lo que podían decir, en algunas ocasiones les facilité referencias de los modelos europeos que se habian tomado en consideración y que podían invocar en el debate, aunque bastantes diputados procuraron no meterse en un terreno que no conocian.

Por mi cuenta, las intervenciones parlamentarias que me correspondió asumir, en que mucho me temo que prevalecía el tono profesoral del catedrático que acudia todos los lunes a la Facultad de Derecho de Oviedo a impartir dos lecciones por la mañana y otras tantas por la tarde, mi manejo de los modelos foráneos era notorio. Eso me ocurrió no solo durante el proceso constituyente, sino también en toda la legislatura siguiente, es decir, a lo largo del desarrollo de la Constitución en la legislación orgánica y en algunas leyes ordinarias. Esta pregunta de su prestigiosa revista me sugiere que quizá debo pensar en ordenar cronológicamente o por materias esos discursos parlamentarios, en el contexto de debates transcendentes, pero hoy olvidados, para publicarlos, pues podrían 
resultar de interés para los constitucionalistas españoles que tienen la suerte de ser notablemente más jóvenes.

En cuanto a los autores de Derecho Constitucional europeo que actuaban como referentes para nosotros en la fase constituyente, también quise dejar constancia en mi citado "Comentario sistemático", en que, al término de la glosa de los preceptos de cada Título de nuestra Ley de Leyes, incorporé una "bibliografia seleccionada sobre la materia", que junto a los autores españoles tomados en consideración menciono la aportación de constitucionalistas extranjeros que tuve más presentes. Las referencias ahí constatadas y las lagunas que puedan observarse son el reflejo fiel de lo que entonces habia dado vueltas por nuestra limitada cabeza profesoral.

HC.- De todos los Títulos constitucionales, quizás el más complejo de abordar fue el relativo a la organización territorial del Estado, que dio lugar a un tanto confuso articulo segundo y a la actual versión del Titulo VIII. ¿Considera Vd. que lo que se hizo entonces era la mejor de las opciones posibles? Si tuviera ocasión de volver a intervenir en el proceso constituyente, y a tenor de la experiencia vivida en estos cuarenta años, ¿cambiaría algo del diseño constitucional de la organización territorial del Estado?

Al contestar a alguna de las preguntas anteriores creo haber respondido ya algo a esta, pero procuraré arrojar cierta dosis adicional de luz.

Aunque nunca tuve una respuesta completa para las cuestiones que me planteaba sobre porqué se hizo correr la lista de Madrid, para incorporarme al Congreso de los Diputados, cuando debía empezar sus trabajos la Comisión, tuve la impresión de que el Ministro de Justicia, Landelino Lavilla, estaba preocupado con el texto que por la Ponencia se había consensuado sobre el Título VIII. Posiblemente quiso incorporar al ancho trabajo que quedaba pendiente a un joven catedrático de Derecho político que procurase racionalizar el texto que sobre el Título VIII había producido la ponencia.

El sigiloso secreto que rodeó los trabajos de la Ponencia no permitió tener noticias precisas ni sobre la gestación de este Título, ni sobre sus trabajos. No obstante, parece claro que unas partes significativas de su Informe se deben a la mayoria que los tres ponentes de UCD conformaron con el ponente de la minoría catalana, Miguel Roca; y entre esas zonas del Informe se encontraba la materia relativa a la ordenación territorial del Estado y especialmente a las comunidades autónomas. Se optó por una combinación de contenido mínimo y de apertura de la fórmula constitucional sobre la materia. Esto conllevaba una importante amplitud de lo delegado por el poder constituyente en materia de ordenación territorial del poder político, a favor del poder estatuyente. Y significaba también que la construcción de nuestro Estado autonómico se iba a convertir en el más dificultoso proceso de desarrollo de una Constitución europea de cuantos recordamos. El no optar por alguna modalidad de Estado Federal significaba, en mi modesta opinión, desconstitucionalizar en gran medida esta materia capital. Ni siquiera la Constitución estableció un mapa de comunidades autónomas incluso se había propiciado un proceso fáctico de preautonomias que en parte aportaba algunas soluciones y también en parte impedia al poder constituyente racionalizar en base a modelos funcionales lo que se había improvisado en base a los intereses de parte de una incipiente clase política. La Constitución establecía 
que la Nación española estaba integrada por nacionalidades y regiones, pero ni se había especificado de qué Comunidades era predicable una u otra condición, ni se había convenido si de tal distinción se derivaban diferencias de tratamiento jurídico-político.

Creo que mi visión era similar a la de Gregorio Peces-Barba y todo ello pudo explicar que el ponente socialista defendiese una enmienda a todo el Título, para su sustitución por una propuesta de carácter federal, que incluía unas listas de competencia cerradas, lo que consta en el correspondiente Boletín Oficial de las Cortes que transcribió esa y las restantes enmiendas. Hago esta referencia, porque no se suele recordar que estuvo sobre la mesa de la Ponencia una propuesta más razonable -por lo que tengo entendido, en buena medida debida a la pluma de Miguel Satrústegui- que, desde el conocimiento del modelo teórico de los federalismos vigentes en Europa y también de la realidad de su aplicación práctica, optaba por la federalización. Pero al nacionalismo catalán no le interesaba un modelo cerrado de carácter federal, pues su plan era el de ir progresivamente ganando competencias sobre nuevas materias, ir paulatinamente desnudando al Estado de ámbitos competenciales en Cataluña, obtener transferencias sucesivas de nuevas competencias y de más funcionarios... de manera que se llegase -quizás en dos generaciones- a una situación en que las fuerzas nacionalistas controlasen prácticamente por entero la educación primaria, secundaria y superior, todos los medios de comunicación públicos (prensa, radios, televisiones, agencias...), la gestión de cuantos servicios públicos interesan a la ciudadanía y la concesión de las ayudas propias de las politicas sociales en favor de los más necesitados, e incluso procurando introducirse en terrenos, como el de las relaciones internacionales, que por su propia naturaleza obviamente no competen a los estados federados.

Concurría la circunstancia de que el ponente Manuel Fraga no quería ni oír hablar del federalismo, lo que a mi me parecía algo huérfano de toda lógica, pero que quizá podia entenderse desde sus alergias ideológicas. Y a mi buen amigo Jordi Solé, según parece, le pareció bien el diseño abierto que pilotaba la fina inteligencia de Miquel Roca. Todo ello significaba que la tesis federal que defendió Gregorio Peces-Barba en nombre del PSOE no pudo encontrar apoyos en Ponencia. Y cuando yo me incorporé a los trabajos constituyentes, prometí a Gregorio apoyarle en todo lo posible, pero al intentarlo en el seno de los cuadros de UCD tropecé con las citadas alergias ideológicas hacia el federalismo. No he olvidado la primera de las muchas entrevistas que celebré con Adolfo Suarez en su despacho; fue en enero de 1978, en que le expuse mi plena disconformidad con el enfoque y con el texto de los preceptos del Título VIII, a la vez que le pedí apoyo para formar un eje con el PSOE para defender una solución federal más o menos a la alemana, que aportaba las ventajas que le expuse. El Presidente, con las buenas formas que en él eran habituales, me espetó que el federalismo había fracasado en España durante la I República. Y cuando yo le dije que el proyecto de constitución federal ni siquiera empezó a discutirse en las Cortes, pues el reverdecer de la guerra carlista absorbió toda la atención de los parlamentarios, él se quedó de piedra y me cambió la conversación.

El Título VIII contenía, casi exclusivamente, de una parte, las vías y procedimientos de acceso a la autonomía y, de otra, el establecimiento de techos competenciales máximos y mínimos en términos manifiestamente mejorables. 
Esta cuasi desconstitucionalización se canalizaba a través del llamado principio dispositivo, que -amen del denominado derecho de autonomía a la hora de acceder a ella, hoy ya esencialmente periclitado- establecía unas bases para la distribución de competencias, sin precedentes en el Derecho comparado y que podian propiciar toda suerte de tensiones. Era la distribución de competencias "a la carta" es decir, a gusto del consumidor, prescindiendo de la racionalidad de la estructura del Estado resultante. Más que de un consenso constituyente, se trató de la incapacidad de alcanzar un consenso federal en sede constituyente. Solo fue lo que años después Roberto Blanco Valdés adjetivó bien como un compromiso apócrifo.

Sobre el valor del aguado marco constitucional en materia de competencias, hay posiciones doctrinales diversas, a las que no es preciso referirme pues son bien conocidas. Pero en todo caso el principio constitucional de apertura era y es disfuncional y propenso a asimetrias competenciales -otra cosa son, por supuesto, las asimetrias naturales que derivan de lenguas propias, fenómenos insulares, comunidades costeras o sin litoral, tradiciones forales y alguna otra, muy pocas si hemos de ser sinceros, "diferencia natural"- que dificultan una articulación de la Administración centrada, racional y exenta de duplicidades conflictivas. Pero lo que no debía servir de legitimación a una asimetría entre las comunidades autónomas era su historia, como creo que había puesto de relieve el debate entre Azaña y Ortega en las Cortes constituyentes de 1931. EL historicismo neo romántico solo servía a fines del siglo XX como caldo de cultivo para nacionalismos, pero a nosotros nos parecía inquietante su asunción como ingrediente de un proceso constituyente. Creo que frente al poder constituyente nunca hay derechos históricos adquiridos. Las disposiciones transitorias primera y segunda no constituyen aciertos del proceso constituyente; más bien han configurado un sendero arcaico que ha conducido a sensaciones de agravios en otras tierras de España y a discursos simplistas desde nacionalismos radicales que solo pretenden negar la condición de España como Nación para lograr, vía secesión su propio Estado. Me ocupé de todo ello con mayor extensión en el discurso de ingreso que redacté y aporté a la Academia de Ciencias Morales y Politicas, publicando su texto ampliado en un librito que hoy mantiene toda su actualidad: "Del consenso constituyente al conflicto permanente" (2010).

Llegado el momento de elaborar los primeros Estatutos de Autonomía, la visión que Adolfo Suarez y buena parte de los politicos de UCD tenian sobre la materia no había cambiado gran cosa. El proyecto de Estatuto, denominado de Sau, que el Parlament de Catalunya remitió al Congreso, a fines de 1979, contenía en su artículo 9 un amplio número de competencias exclusivas de la Generalitat, entre las que figuraban cinco que a su vez se encontraban en la relación de competencias exclusivas del Estado (Art. 149.1 CE). Por entonces el modesto profesor que contesta esta encuesta habia rechazado ya educadamente la cartera de educación que el Presidente Suarez le había ofrecido tras la celebración de las elecciones generales de 1979, para asumir la condición de Portavoz de UCD en la Comisión de Asuntos Constitucionales del Congreso de los Diputados. En el desempeño de esa función me responsabilicé de redactar y presentar nuestras enmiendas a dicho proyecto y naturalmente incluí las relativas a la mencionada asunción por la Generalitat como competencias exclusivas de varias que la Constitución atribuía al Estado. En las negociaciones 
subsiguientes, todas celebradas en sesiones de trabajo larguísimas celebradas en el Palacio de la Moncloa, fui enteramente inflexible en una materia que entendí no negociable por imperativo de la Constitución vigente. Se llegó a un momento en que se había avanzado bastante en los diálogos, pero en este punto no se había podido dar ni un solo paso. Por lo que se me dijo, parece que Miquel Roca habló por teléfono con Tarradellas para que este hablase con Adolfo Suarez y pidiese una reunión en Madrid a la que vendría también Jordi Pujol. El Presidente del Gobierno accedió a esta solicitud y se celebró en la Moncloa una larga sesión de trabajo en el despacho del Presidente, a la que finalmente no acudió Tarradellas, pero si Pujol, de manera que el diálogo se mantuvo de una parte entre Adolfo Suarez acompañado por el Ministro de la Presidencia, José Pedro Pérez Llorca, y, de otra, entre Jordi Pujol y Miquel Roca. Al término de la misma se me informó de su fruto: se había transado una fórmula inspirada en la cuadratura del círculo: "Es competencia de la Generalitat la materia..., sin perjuicio de lo dispuesto en el número $\mathrm{X}$ del apartado 1 del artículo 149 de la Constitución". Esas competencias se convirtieron así, por vía a mi juicio inconstitucional, de exclusivas en compartidas, ante la perplejidad del joven profesor que entonces era. Y naturalmente la pseudo solución se traspasaria al Estatuto de Autonomía del País Vasco y a algún otro. Como todo aquello me parecía imposible de defender, seguí desempeñando mi rol de portavoz en la Comisión, pero sin hacer uso de la palabra ni en el debate habido sobre el Estatuto de Cataluña, ni sobre los demás, pues mi condición de profesor siempre prevaleció sobre mi status transitorio en aquella importante etapa de nuestra vida política.

Aunque intentaba, sin éxito, disimular el calibre de mi enfado, el Presidente Suarez, con su inigualable simpatía personal, me citó en su despacho para darme toda suerte de explicaciones y para decirme que me iba a condecorar, junto a los otros ponentes del Estatuto de Cataluña, con la Gran Cruz de Isabel la Católica. Le contesté, con el debido tacto, que no lo podía aceptar pues ello contravenía lo dispuesto en el artículo 130 de la Constitución gaditana de 1812. Artículo del que naturalmente Suarez no había oído hablar y pensaba, con razón, que no estaba vigente. Pero le resumí lo que decía este precepto y el que le precedía y la posición de nuestros primeros liberales, reunidos en Cádiz sobre que el gobierno no otorgase las entonces muy importantes condecoraciones a diputados, que en mi opinión seguía siendo moderna y aplicable a la incómoda situación en que más de una vez se encuentra un profesor que se ve sumergido en las dinámicas de los politicos profesionales.

En resumen, al Título VIII, dicho sea con el debido respeto, no es fácil dedicarle elogios. He defendido siempre que habia que reformarlo en dirección hacia una solución federal. Pero el bipartidismo imperfecto español impregnó al pragmatismo de gran parte de nuestros politicos profesionales de una idea motriz: el partido más votado en las elecciones generales podía gobernar, pese a no haber obtenido mayoría absoluta en el Congreso, con el apoyo de las fuerzas nacionalistas adquirible a base de transferir recursos, funcionarios $y$ competencias, entre otras vías por la del artículo 150.2 de la $\mathrm{CE}$, que ha permitido ir derogando en la práctica el listado de competencias exclusivas del Estado que contiene el artículo 149.1 de nuestra Norma Fundamental sin pasar por su Título X. 
HC.- Historia Constitucional es una revista, obviamente, que mira sobre todo hacia el pasado, y por eso resulta inevitable que le preguntemos su opinión sobre qué aspectos de nuestra historia constitucional considera que en el proceso constituyente se tuvieron presentes para diseñar la Constitución del 78, pero también cuál considera Vd. que es el elemento (o elementos) más rupturista e innovador de nuestra actual Constitución en relación con las Constituciones

Durante nuestro proceso constituyente, estábamos alejados de las líneas maestras de nuestra historia constitucional, con constituciones que nunca se reformaron, amén de que quienes protagonizaron los pronunciamientos militares no se solían tomar la molestia de derogar la hasta entonces Constitución vigente. Recuerdo que cuando, en segundo curso de licenciatura, el maestro Ruiz del Castillo, explicó en una de sus clases las principales aportaciones a la cultura jurídico-política occidental del constitucionalismo británico y del norteamericano, amén del francés, un alumno le preguntó que había aportado nuestra historia constitucional; a lo que D. Carlos le contestó con una abierta sonrisa: "el cuartelazo". Su fino sentido del humor quizá no andaba muy descaminado. No obstante, procuraremos contestar algo a tan dificil pregunta.

La operación de la reforma política, se había pilotado, como es obvio desde el extremo conservador del espectro político de la época, por quienes a ciertos efectos se inspiraron en la fórmula de carta otorgada de que se había servido la Corona al dictar el Estatuto Real de 1834. Naturalmente habia transcurrido casi siglo y medio y el escenario era otro muy diferente. No obstante cabe pensar que algunos de ellos tenían presente el Senado de nuestro siglo XIX, concebido como una Cámara Alta en que se sentaba la tradición histórica, en forma solo parcialmente diferente a la encarnada por la Cámara de los Lores en el constitucionalismo británico. También entre los postfranquistas influyentes en el proceso de la Transición se prefería nuestro sistema electoral mayoritario del siglo XIX, al proporcional propugnado en aquellos años por la oposición democrática al Régimen.

No pretendo en este trance profundizar en el complejo pacto constituyente sobre la composición del Senado y del Congreso de los Diputados, así como sobre sus respectivos sistemas electorales, que es materia imposible de explicar con la parquedad inherente al género literario que nos ocupa. Pero creo que cabe afirmar que tanto en los debates constituyentes, como en el seguimiento de los mismos por parte del profesorado de nuestra disciplina, prevalecía la opinión de que las soluciones no debían buscarse preferentemente en una historia juridicopolítica en que es verdad que arrancó en las brillantes Cortes de Cádiz, que dieron a luz una gran Constitución. Pero no fue menos cierto que seguidamente tuvimos una muy modesta tradición constitucional. Escribí en su día que nuestros partidos decimonónicos defendian unas ideas políticas a las que no pensaban traicionar con pactos o transacciones suscritos con quienes actuaban desde otras tesis ideológicas, de forma que cada partido defendía un modelo de organización de la vida política, en ciertos aspectos, antagónico al preconizado por otras fuerzas políticas. Frecuentemente cada partido incorporaba a su programa un modelo de Constitución, que aspiraba a implantar tan pronto como alcanzase el poder, suprimiendo, claro está, la vigencia de la Constitución que había sido aprobada durante el mandato de un Gobierno anterior apoyado en otro partido. 
Es decir, si una Constitución puede ser entendida como decisión unilateral de un solo partido o como solución de consenso alcanzada por varias fuerzas politicas, hemos de reconocer que nuestra historia constitucional ha estado plagada de constituciones del primer tipo, de constituciones decisionistas, si se nos permite extrapolar la terminología de Donoso Cortés, con la relativa salvedad de la Constitución de 1837 y de la Constitución canovista de 1876 . Y esto por no hablar de otro factor de no menor transcendencia, a saber, el clima de Guerra Civil que coexistió con nuestra historia constitucional del siglo XIX y de buena parte del XX. Todo ello en nuestra historia decimonónica patria configuraba un clima de confrontación absoluta, muy alejado de la cultura que durante el mismo siglo se creó y consolidó en buena parte de los países europeos y en Norteamérica, de convivencia de los diversos partidos políticos en el marco de unas reglas constitucionales pactadas y respetadas por todos. Era en estos grandes modelos de Derecho constitucional foráneo en los que, durante nuestra fase constituyente, creímos que debiamos centrar nuestra atención buscando enseñanzas a adaptar a nuestra dura tierra.

No obstante, en los escaños constituyentes se sentaban sensibilidades diversas y aún contrapuestas. Y quienes tenían el propósito de continuar siendo politicos profesionales veían ventajas en la azarosa trayectoria de nuestra historia constitucional. Así, por poner un solo ejemplo, la admiración hacia nuestro Tribunal de Cuentas decimonónico, especializado en mirar hacia otra parte y en fijarse fundamentalmente en ejercicios ya prescritos era notoria en algunos diputados, que venían del sistema anterior. También recordamos la alergia de estos diputados a debatir que sentido conservaban, a fines del siglo XX, las nociones de inviolabilidad o de aforamiento de los parlamentarios.

En la modesta opinión de quien contesta a estas preguntas de Historia Constitucional, que sabe mucho menos de nuestro constitucionalismo histórico que quienes dirigen esta magnífica publicación, el capítulo de que podemos estar más orgullosos de nuestro devenir constitucionalista es el de las Cortes de Cádiz y su interesantísima Constitución de 1812, que como es bien sabido se convirtió en su época en uno de los grandes referentes en la materia, junto con el constitucionalismo británico, la breve Carta Magna norteamericana de 1787 y la Constitución francesa de 1791. Reconozco ser un forofo de los debates gaditanos, del clima creado por los liberales españoles en torno a lo que la Europa de la época denominó la Revolución española y naturalmente intenté, junto con bastantes otros amigos que compartían esta visión, que algunas de las soluciones de nuestra gloriosa pepa fuesen tenidas en cuenta. Así, en la constitucionalización de buena parte de los derechos de los justiciables nuestra primera Constitución, como tuve ocasión de exponer pormenorizadamente en una de las sesiones de mi Academia de Ciencias Morales y Politicas ${ }^{1}$, consagra ciertas garantías puntuales que son pioneras en la historia del constitucionalismo universal. Recordemos varios ejemplos: el artículo 291 doceañista rezaba: "la declaración del arrestado será sin juramento, que a nadie ha de tomarse en materias criminales sobre hecho propio", solución innovadora que fue

1 Vid. "La justicia en la Constitución española de 1812", en Anales de la Real Academia de Ciencias Morales y Politicas, 2012, pp. 347 a 388. Recogido en ALZAGA, O.: "Sociedad democrática y Constitución. (Estudios y cabos sueltos)", Marcial Pons, Madrid 2018, pp. 75 y ss. 
incorporada al artículo 24.2 de nuestra Constitución. El precepto 247 de nuestra Constitución gaditana dispuso: "Ningún español podrá ser juzgado ... sino por el tribunal competente determinado con anterioridad por la ley", esencialmente transcrito en el art. 24.2 de nuestra Constitución vigente: "Todos tienen derecho al juez ordinario predeterminado por la ley".

Traigo a colación estos ejemplos para disipar las dudas acerca de que no se recordaba en nuestro proceso constituyente el extenso y buen texto magno gaditano, aunque su peso en 1978 era infinitamente menor al que ejercian las grandes constituciones europeas vigentes. La distancia entre el primer constitucionalismo europeo y el contemporáneo era ya enorme y en nuestras Cámaras constituyentes prevalecía el deseo de incorporarnos a una Europa democrática de la que deseábamos formar parte. La homologación de nuestras instituciones políticas con las de los países miembros de esa admirada Europa tenía demasiada fuerza como para pensar en un diseño constitucional presidido por la idea romántica de conectar con nuestro constitucionalismo histórico.

HC.- En la misma linea, resulta evidente que el referente histórico más cercano y directo era la Constitución de la Segunda República. ¿En qué medida la Constitución del 31 fue empleada en los debates constituyentes, ya fuese para convertirla en referente, ya para rechazar frontalmente ese modelo?

La Constitución de 1931 ha gozado siempre de mi mayor respeto. Antes he tenido ocasión de citar a mi maestro, Carlos Ruiz del Castillo. Aunque yo estudié con él los dos cursos de nuestra asignatura por los apuntes que tomé en sus clases, para asegurarme como buen empollón que sacaba sendas matrículas de honor, adquirí en una librería de viejo su magnífico manual de Derecho Político, escrito durante la vigencia de esta Lex Normarum republicana, que aún hoy constituye uno de los mejores textos que se ha escrito sobre esta Constitución, que tenía aspectos muy modernos, pero cuya vida fue interrumpida por el golpe de 1936. Ruiz del Castillo que fue Magistrado del Tribunal de Garantías bajo la vigencia del texto del treinta y uno conservó toda su vida un especial respeto por muchas de las soluciones que allí se consagraron.

En nuestras constituyentes, latía la prudencia de la transición y por ello se citó poco en los debates nuestra Constitución de la II República. Sin embargo, hubo referencias más o menos puntuales, pero que no constituian un mero adorno. Recuerdo bien las referencias al texto de 1931 que formularon parlamentarios del Partido Nacionalista Vasco en torno a la materia del Título VIII. Pero también hubo algunas menciones de esta índole sobre cuestiones relativas a la organización y al funcionamiento de determinadas instituciones, como por ejemplo en el debate sobre la composición del Tribunal Constitucional, materia en la que no faltaron sugerencias desde las fuerzas nacionalistas para que existieran miembros del Tribunal Constitucional propuestos por las Comunidades Autónomas y ese antecedente de la Constitución de 1931, que concedió este rol a las regiones no había sido positivo, pero lo cierto era que no dejaba de estar en el museo del constitucionalismo histórico español. Dejando ahora a un lado que aquella contienda se resolvió considerando que los cuatro miembros del Tribunal propuesto por el Senado cumplirian ese papel. Fue interesante escuchar la intervención del portavoz socialista, Gregorio PecesBarba, en el Pleno del Congreso (Diario de Sesiones de 20 de julio de 1978) 
justificando por qué no se habian seguido ciertas pautas marcadas, en cuanto a la composición del Tribunal de Garantías Constitucionales, por la Constitución republicana. Fueron palabras explicativas dirigidas a los escaños del propio PSOE, donde se sentaban algunos congresistas -sobre todo los de mayor edadidentificados con la trayectoria republicana de su partido. He tenido ocasión de referirme en un artículo" a esta cuestión y dejé anotado que "gravitó sobre los constituyentes socialistas el recuerdo de la Constitución de nuestra II $^{\mathrm{a}}$ República", y planteando que está pendiente de abordar entre nosotros "en qué pequeña medida asumieron tal modelo y tradición y en qué forman obviaron seguir en lo fundamental las pautas de dicho precedente". Y añadíamos que "cabria estudiar tal problemática también respecto de otros grupos parlamentarios conectados con la experiencia republicana; principalmente es digno de ser analizado en profundidad el caso del Partido Nacionalista Vasco y algún interés tiene quizás este análisis referido a CIU y PCE, por razones que se nos antojan obvias".

Fecha de envio / Submission date: 14/04/2018

Fecha de aceptación /Acceptance date: 02/05/2018

2 "Sobre la composición del Tribunal Constitucional", en Teoría y Realidad Constitucional, núm. $10-11,2^{\circ}$ semestre de 2002 , pp. 149 a 180. 